\title{
The Molecular Composition of Neuronal Microfilaments Is Spatially and Temporally Regulated
}

\author{
Ron Weinberger, ${ }^{1}$ Galina Schevzov, ${ }^{2}$ Peter Jeffrey, ${ }^{1}$ Kylie Gordon, ${ }^{1}$ Mark Hill, ${ }^{2}$ and Peter Gunning ${ }^{2}$ \\ ${ }^{1}$ Developmental Neurobiology and '2Cell Biology Units, Children's Medical Research Institute, Wentworthville, \\ New South Wales 2145, Australia
}

The actin-based microfilament system is thought to play a critical role in neuronal development. We have determined specific changes in the composition of microfilaments accompanying neuronal morphogenesis. By using specific antibodies against the isoforms for tropomyosin (Tm) (Tm-5 and TmBr-1/ -3) and actin ( $\beta$ - and $\gamma$-actin), we found that during early morphogenesis in vivo immature growing axons contain $\beta$ - and $\gamma$-actin and $\mathrm{Tm}-5$. In particular, $\mathrm{Tm}-5$ is exclusively located in the immature axonal processes relative to the neuronal cell body. In contrast, $\beta$-actin and Tm-5 are absent in mature, quiescent axons. This developmental loss from axons is associated with an approximately twofold downregulation of $\beta$-actin and Tm-5 levels in the brain; $\gamma$-actin levels do not change, and this molecule is widely distributed throughout neurons during development. The loss of $\beta$-actin and $\mathrm{Tm}-5$ from axons is accompanied by a progressive appearance of $\mathrm{TmBr}-1 /-3$. This apparent replacement of $\mathrm{Tm}-5$ with $\mathrm{TmBr}-1 /-3$ occurs over a 2 d time period during rat embryonic hindbrain development and is conserved in evolution between birds and mammals. The loss of Tm-5 from axons involves a redistribution of this molecule to the cell soma and dendrites. These findings suggest that specialized microfilament domains are associated with the development and maintenance of neuronal polarity. We conclude that these $\mathrm{Tm}$ isoforms and $\beta$-actin are subject to specific patterns of segregation associated with axonal development and neuronal differentiation. This provides a potential molecular basis for the temporal and spatial specificity of microfilament function during neuronal differentiation.

Key words: microfilaments; actin; tropomyosin; isoforms; neuronal development; Purkinje cells
The integral molecular components of nonmuscle microfilaments are the actin ( $\gamma$ - and $\beta$-actin) and tropomyosin (Tm) isoforms (Mooseker et al., 1981). Tropomyosins are rod-like proteins that bind in a head-to-tail manner and insert into the $\alpha$-helical groove of the actin filaments (Taylor, 1979; Mooseker et al., 1981). At present at least $22 \mathrm{Tm}$ isoforms, derived from four genes, have been identified in the adult mammal (Beisel and Kennedy, 1994; Pittenger et al., 1994). Many of these Tms display tissue or cellular specificity such as the neuronal Tms, TmBr-3, and TmBr-1 (Stamm et al., 1993; Weinberger et al., 1993). This array of microfilament-specific isoforms suggests that microfilament composition may vary between specific cellular compartments.

Evidence for the intracellular molecular heterogeneity of microfilaments has been derived almost exclusively from in vitro cell studies. Microvascular pericytes sort muscle and nonmuscle actin isoforms into discrete cytoplasmic domains (De Nofrio et al., 1989). When monolayers of endothelial and 3T3 cells were injured, $\beta$-actin was found localized in the motile cytoplasm of the wound edge and disappeared upon monolayer restoration (Hoock et al., 1991). This dynamic model revealed that $\beta$-actin was spe-

\footnotetext{
Received June 19, 1995; revised Aug. 23, 1995; accepted Sept. 18, 1995.

This work was supported by National Health and Medical Research Council grants to R.P.W., P.G., and P.L.J. An equipment grant was obtained from the Ramaciotti Foundation to P.G. and M.H. Peter Gunning is a National Health and Medical Research Council Senior Research Fellow. K.G. is a recipient of a University of Western Sydney (Nepean) Postgraduate Scholarship. We thank Dr. Patrick Tam for his advice with regard to the rat embryonic development and Professor Peter Rowe for his critical reading of the manuscript. Christine Smythe provided excellent technical support with the CLSM. The reviewers are particularly acknowledged for help in making the manuscript morc accessiblc.

Correspondence should be addressed to Ron Weinberger, Developmental Neurobiology Unit, Children's Medical Research Institute, Locked Bag 23, Wentworthville, New South Wales 2145 , Australia.

Copyright $(\mathcal{O} 1995$ Society for Neuroscience $0270-6474 / 95 / 160238-15 \$ 05,00 / 0$
}

cifically recruited to the leading edge of the cell for motility. $\beta$-Actin was also excluded from a specific region of the smooth muscle contractile apparatus (North et al., 1994). The Tm-5 isoform(s) have been found to be localized to both stress fibers and the ruffling edges of fibroblasts, in contrast to the larger molecular weight Tms that were found localized only to stress fibers, indicating molecularly distinct subsets of microfilaments in these cells (Lin et al., 1988).

Recent studies have shown that in addition to sorting specifically, microfilament isoforms are functionally distinct. Studies in which human $\beta$ - and $\gamma$-actin genes were stably transfected into $C 2$ myoblasts revealed that the protein isoforms can dramatically affect cellular morphology even though they differ in primary amino acid sequence by only four amino acids (Schevzov et al., 1992). This may result, at least in part, from the interactions between the various actin and Tm isoforms (Schevzov et al., 1993). Indeed, it has been proposed on the basis of mutant yeast (Liu and Bretscher, 1989, 1992) and in vitro studies (for review, see Pittenger et al., 1994) that interactions between actin and Tm can regulate microfilament stability. Therefore a switch in $\mathrm{Tm}$ isoforms may be potentially important in the control of the organization of microfilaments within the cell, which may result in altered cellular function. The developmental regulation of these isoforms and their localization to specific cellular compartments is likely to have significant implications for neuronal function.

The development of specific antibody probes for Tms has been hampered by the large regions of homology between the isoforms. We have devcloped a pancl of antisera raiscd against synthetic peptides modeled on unique regions of the Tms. In this study we show that both the levels and localization of specific Tm and actin isoforms are developmentally regulated, resulting in molecularly 
A $\begin{array}{lllllllllllllll}1 a & 2 a & 2 b & 1 b & 3 & 4 & 5 & 6 a & 6 b & 7 & 8 & 9 a & 9 b & 9 c & 9 d\end{array}$

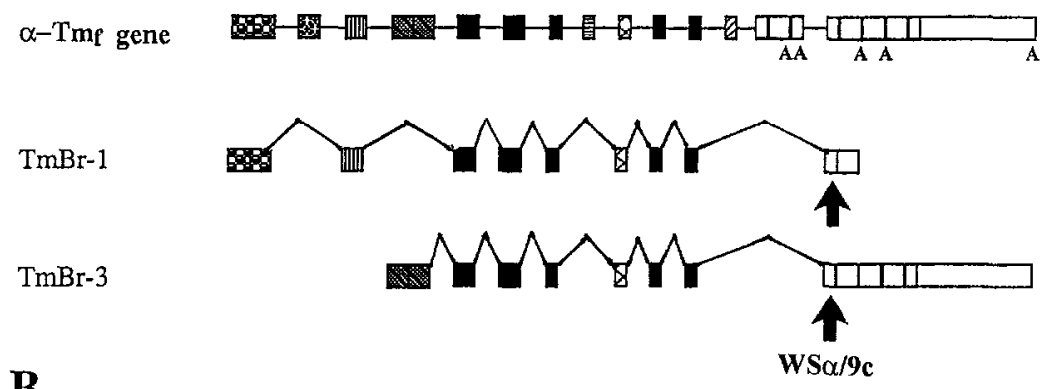

$\alpha-\operatorname{Tm}_{s}$ gene

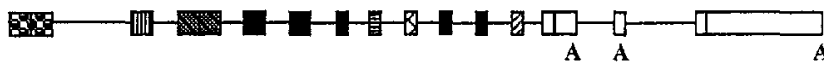

Tm-5 (NM1)

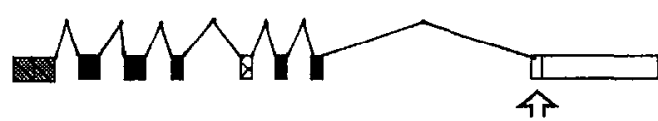

Tm-5 (NM2)

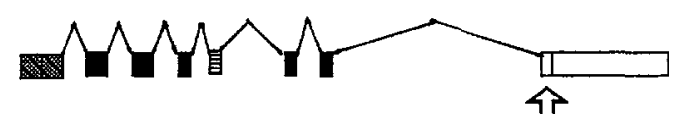

WS5/9d
Figure 1. $\alpha-\operatorname{Tm}_{\mathrm{f}}$ and $\alpha-\mathrm{Tm}_{\mathrm{s}}$ gene structure and the isoforms potentially identified by the antisera used in this study. Exons are represented by boxes and introns are represented by lines. The letter $A$ beneath the genes refers to the location of polyadenylation sequences. The numbering system of exons $1 \mathrm{a}$ to $9 \mathrm{~d}$ is maintained between the two genes to facilitate comparison. This system is based on the nomenclature of Lees-Miller et al. (1990). The description of the $\alpha$-Tm $\mathrm{s}$ gene is a combination of data obtained from human (Clayton et al., 1988) and rat (Beisel and Kennedy, 1994) genes. Only the relevant mRNA transcripts derived from these genes are presented. The reader is referred to Lees-Miller et al. (1990) $\left(\alpha-T m_{f}\right)$ and Beisel and Kennedy (1994) $\left(\alpha-T m_{s}\right)$, for a list of the transcripts identified from these genes to date. The WS $\alpha / 9 \mathrm{c}$ antiserum was raised against a peptide sequence coded by exon $9 \mathrm{c}$ (arrow, $A$ ) of the $\alpha$-Tm $\mathrm{f}$ gene and therefore potentially identifies TmBr-1 and $\mathrm{TmBr}-3(A)$. The WS5/9d antiserum was raised against a peptide sequence coded by exon $9 \mathrm{~d}$ (arrow, $B$ ) of the $\alpha-\mathrm{Tm}_{\mathrm{s}}$ gene and therefore potentially identifies NM1 and NM2 $(B)$. distinct microfilament domains that differ between neuronal compartments.

\section{MATERIALS AND METHODS}

Antibody production. Initially, synthetic peptides based on unique $\mathrm{COOH}$ terminus sequences were synthesized (Macromolecular Resources, Fort Collins, CO). Peptide 1 was based on amino acids 222-227 (DKLKCT) of the mammalian nonmuscle Tm-5 sequence derived from exon $9 \mathrm{~d}$ of the $\alpha-\mathrm{Tm}_{\mathrm{s}}$ gene (Clayton et al., 1988). Peptide 2 was modeled on exon $9 \mathrm{c}$ of the rat $\alpha-\mathrm{Tm}_{\mathrm{f}}$ gene that encodes the sequence comprising amino acids 261-281 of TmBr-1 and 225-245 of TmBr-3 (HQLQQNRRLTNELKLALNED, Lees-Miller et al., 1990). Both peptides were conjugated to keyhole limpet hemocyanin. Peptide 1 was conjugated via a tyrosine residue adjacent to the threonine, and peptide 2 was conjugated via a cysteine adjacent to the histidine. Both peptides were dissolved in phosphate-buffered saline (PBS), pH 7.4, before injection. In the case of peptide 1 , conjugated peptide was initially injected intramuscularly in a Freund's complete adjuvant emulsion into 12-week-old New Zealand White rabbits. The first boost injection was administered $18 \mathrm{~d}$ after the primary injection and the second boost 5 weeks later, after which the animals were exsanguinated. At each injection $2 \mathrm{mg}$ of peptide was used. An identical injection regimen was used with peptide 2 , with the exception that the $2 \mathrm{mg}$ injected at each interval comprised $0.5 \mathrm{mg}$ unconjugated peptide and $1.5 \mathrm{mg}$ conjugated peptide. Antibody titer was assessed by ELISA or dot blot using the unconjugated peptides as antigens. Antisera (WS5/9d and WS $\alpha / 9 \mathrm{c}$ ) were then tested by Western analysis and by immunohistological techniques for their potential use. $\beta$-Actin monoclonal antibody (North et al., 1994) was kindly supplied by Dr. H. Langbeheim, and the $\gamma$-actin polyclonal antibody was supplied by Dr. J. C. Bulinski. The TM 311 antibody (a nonisoform-specific Tm antibody) was obtained from Sigma (St. Louis, MO). Commercial primary antibodies used were an antimicrotubule-associated protein 2 (MAP-2) antibody (Amersham, Buckinghamshire, England) and a monoclonal antibody that specifically recognizes the highly phosphorylated form of the $200 \mathrm{kDa}$ component of neurofilaments (NF-Hp, Sternberger Monoclonals, Baltimore, $\mathrm{MD}$ ).

Tissue preparation for microscopy. Tissues were prepared for embedding in soft polyester wax (BDH, Poole, England), as described in Sheppard et al. (1988). Briefly, immediately after dissection, the tissue was immersed for $6 \mathrm{hr}$ at $4^{\circ} \mathrm{C}$ in $5 \% \mathrm{v} / \mathrm{v}$ glacial acetic acid in absolute ethanol with changes, dehydrated, and embedded. Sections were cut to $4 \mu \mathrm{m}$ thickness unless otherwise described (Sheppard et al,, 1988). All slides were dewaxed in 50\% xylene $/ 50 \%$ ethanol and then rehydrated as described previously.
Immunohistochemical labeling. Nonspecific binding was blocked by a preliminary incubation with $10 \% \mathrm{v} / \mathrm{v}$ normal goat serum (NGS) in PBS, $\mathrm{pH}$ 7.4. This was followed by incubation for $1 \mathrm{hr}$ with the primary antibody in a solution of $2 \%$ NGS $(\mathrm{v} / \mathrm{v}) / \mathrm{PBS}, \mathrm{pH} 7.4$. All primary antibodies were routinely used at a dilution of 1:500. The sections where then washed two times in PBS. Subsequently the diluted secondary antibody [2\% NGS (v/v) PBS, pH 7.4] was applied for $1 \mathrm{hr}$.

The secondary antibodies used were goat anti-rabbit IgG-alkaline phosphatase (AP) conjugated, rabbit anti-mouse IgG-AP conjugated, fluorescein (DTAF) conjugated goat anti-mouse or anti-rabbit IgG, and rhodamine (TRITC) conjugated donkey anti-mouse or -rabbit IgG (Jackson Immunochemicals, West Grove, PA). The slides were then washed two times for $10 \mathrm{~min}$ when AP-conjugated secondary antibody was used and incubated in a pH 9.5 buffer $(0.1 \mathrm{M}$ Tris $\mathrm{HCl}, 50 \mathrm{~mm}$ $\mathrm{MgCl}_{2}, 0.1 \mathrm{M} \mathrm{NaCl}$ ) for $5 \mathrm{~min}$; immunoreactivity was visualized by the nitro blue tetrazolium chloride (NBT)/5-bromo-4-chloro-3indolylphosphate-p-toluidine salt (BCIP) color reagent system (Gibco, Gaithersburg, MD).

Western immunoblot analysis and densitometry. SDS-PAGE gels and immunoblot transfers were essentially performed as described by Lloyd et al. (1992), with the exception that the secondary antibody was conjugated to alkaline phosphatase. Protein bands were visualized either by the BCIP/NBT color reagent method or by chemoluminescence (Lumiphos, Boehringer Mannheim, Sydney, Australia). Densitometry of Western blots was performed on the bands obtained on $x$-ray film using the Lumiphos reagent, as described previously (Weinberger et al., 1993).

Microscopy. A confocal laser scanning microscope (CLSM, Wild Leitz Instruments, Heidelberg, Germany) using $25 \times$ and $40 \times$ objectives (1.3 NA) was used to analyze fluorescent label distribution on the sections (Hill et al., 1994). Tissue sections were optically sectioned in the $x-y$ plane (parallel to the substratum, $2 \mu \mathrm{m}$ slices), and all images were stored on optical disk. Slides prepared for light microscopy were visualized using an Olympus $\mathrm{BH} 2$ photomicroscope.

\section{RESULTS}

\section{The antisera WS5/9d and WS $\alpha / 9 \mathrm{c}$ identify specific Tm isoforms in the rat and chick}

$\mathrm{WS} \alpha / 9 \mathrm{c}$ potentially identifies two $\mathrm{Tm}$ isoforms generated from the $\alpha-\mathrm{Tm}_{\mathrm{f}}$ gene, $\mathrm{TmBr}-1$ and $\mathrm{TmBr}-3$, which differ in molecular weight (Fig. 1A) (Stamm et al., 1993). Similarly, WS5/9d may potentially recognize two isoforms from the $\alpha-\mathrm{Tm}_{\mathrm{s}}$ gene, NM1 and NM2 (Fig. $1 \mathrm{~B}$ ), which are based on the predicted amino 


\section{9}

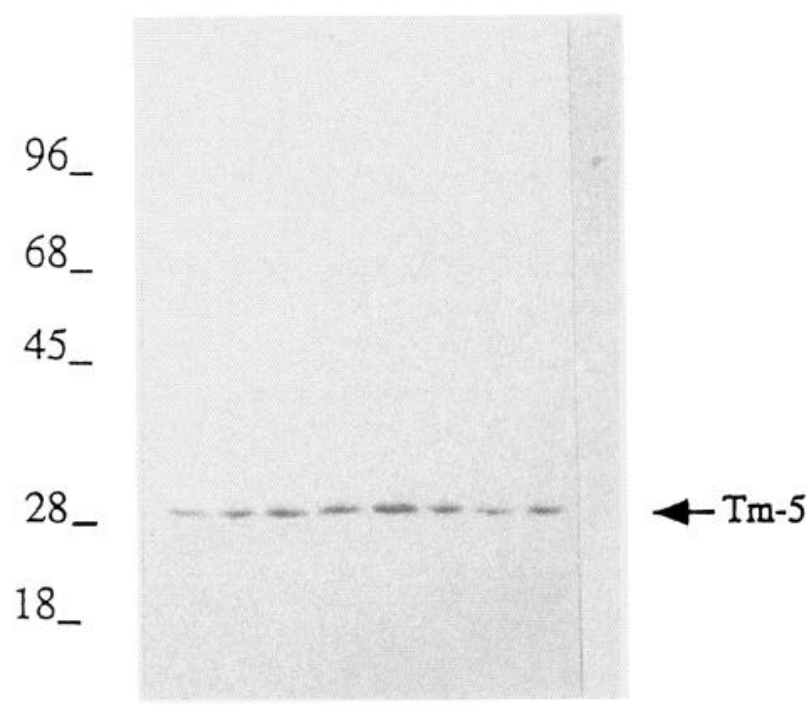

C

D
123

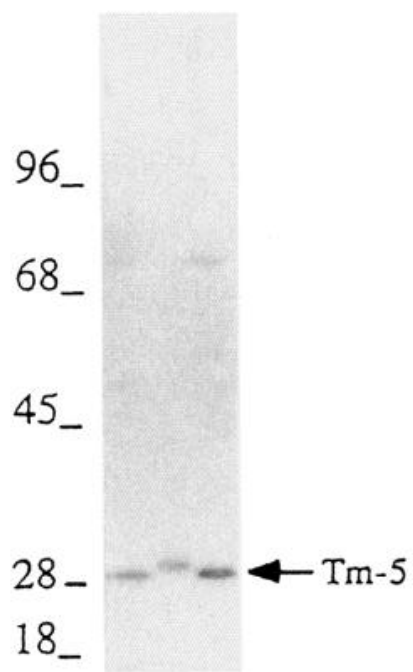

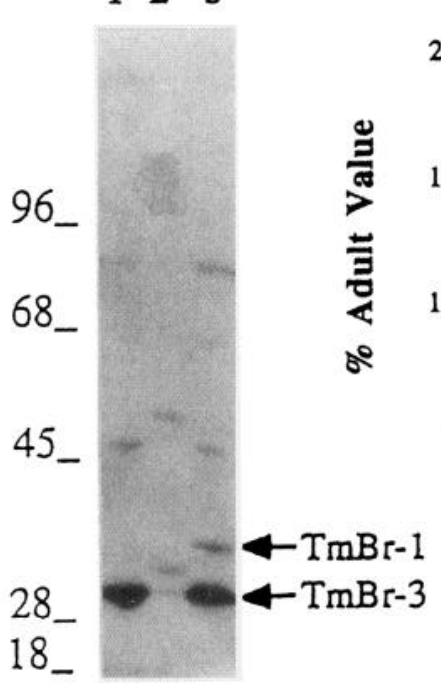

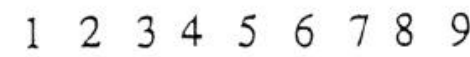

96

68

45

28

18

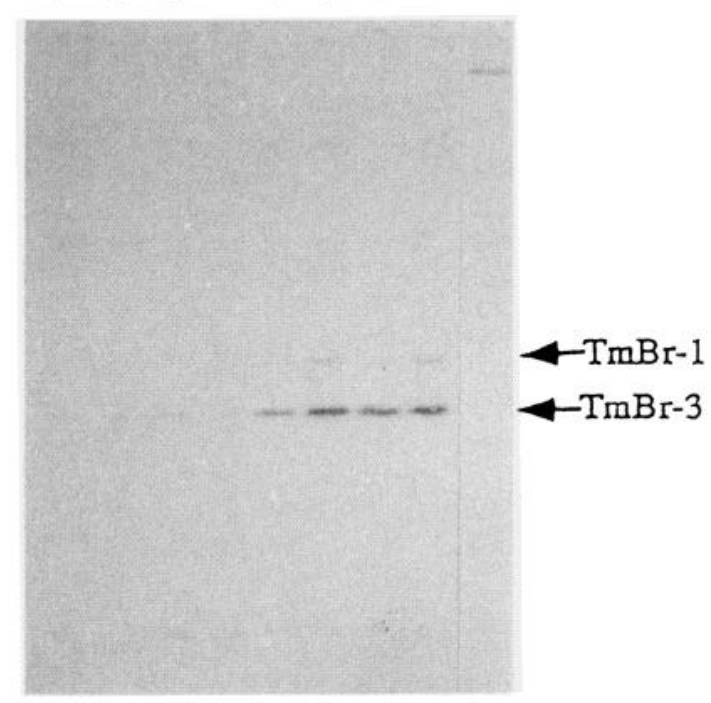

E

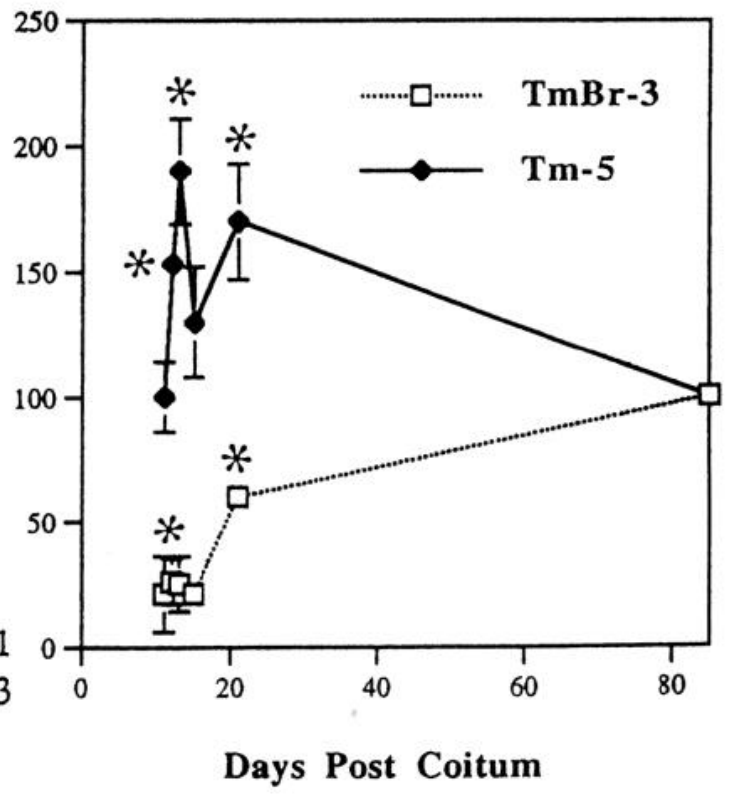

Figure 2. Western immunoblot characterization of antisera and developmental expression of $\mathrm{TmBr}-3$ and $\mathrm{Tm}-5$ in the rat. Fifteen microgram protein samples were separated by SDS-PAGE, transferred to PVDF membranes, and then incubated with appropriate antisera (WS5/9d for $A$ and $C$; WS $\alpha / 9 \mathrm{c}$ for $B$ and $D$ ). Molecular weight markers are indicated on the left side of each blot. Immunoreactivity was visualized as described in Materials and Methods. $A$ and $B$, (1) Embryonic day (ED) 11 whole embryo; (2) ED13 brain; (3) ED14 brain; (4) ED17 brain; (5) newborn brain; (6) adult whole brain; (7) adult cerebellum; (8) adult forebrain; and (9) adult skeletal muscle. All samples are from the rat. Antisera were used at a dilution of 1:400, which is the concentration used for all subsequent immunohistology. $C$ and $D$, (1) Adult rat cerebellum; (2) 2-d-posthatch chick cerebellum; and (3) adult rat forebrain. Antisera were used at a dilution of 1:150. Note the presence of nonspecific bands at $70-75 \mathrm{kDa}$ in the rat samples that are absent at a dilution of 1:400 (compare with $A$ and $B$ ). Two-dimensional gel electrophoresis revealed only one spot migrating at the apparent molecular weights of Tm-5, $\mathrm{TmBr}-3$, and $\mathrm{TmBr}-1$ (not shown). E, Densitometric quantitation of $\mathrm{Tm}-5$ and $\mathrm{TmBr}-3$ bands obtained by Western blot analysis from rat brain developmental time courses $(n=5)$. Values were calculated as arbitrary optical density units/microgram protein and then expressed as a percentage of the adult value for either Tm-5 or TmBr-3 (mean $\pm \mathrm{SD}$ ). The asterisk indicates that the values are statistically different from those of the adult $(p<0.0025)$, as determined by Student's $t$ test. 

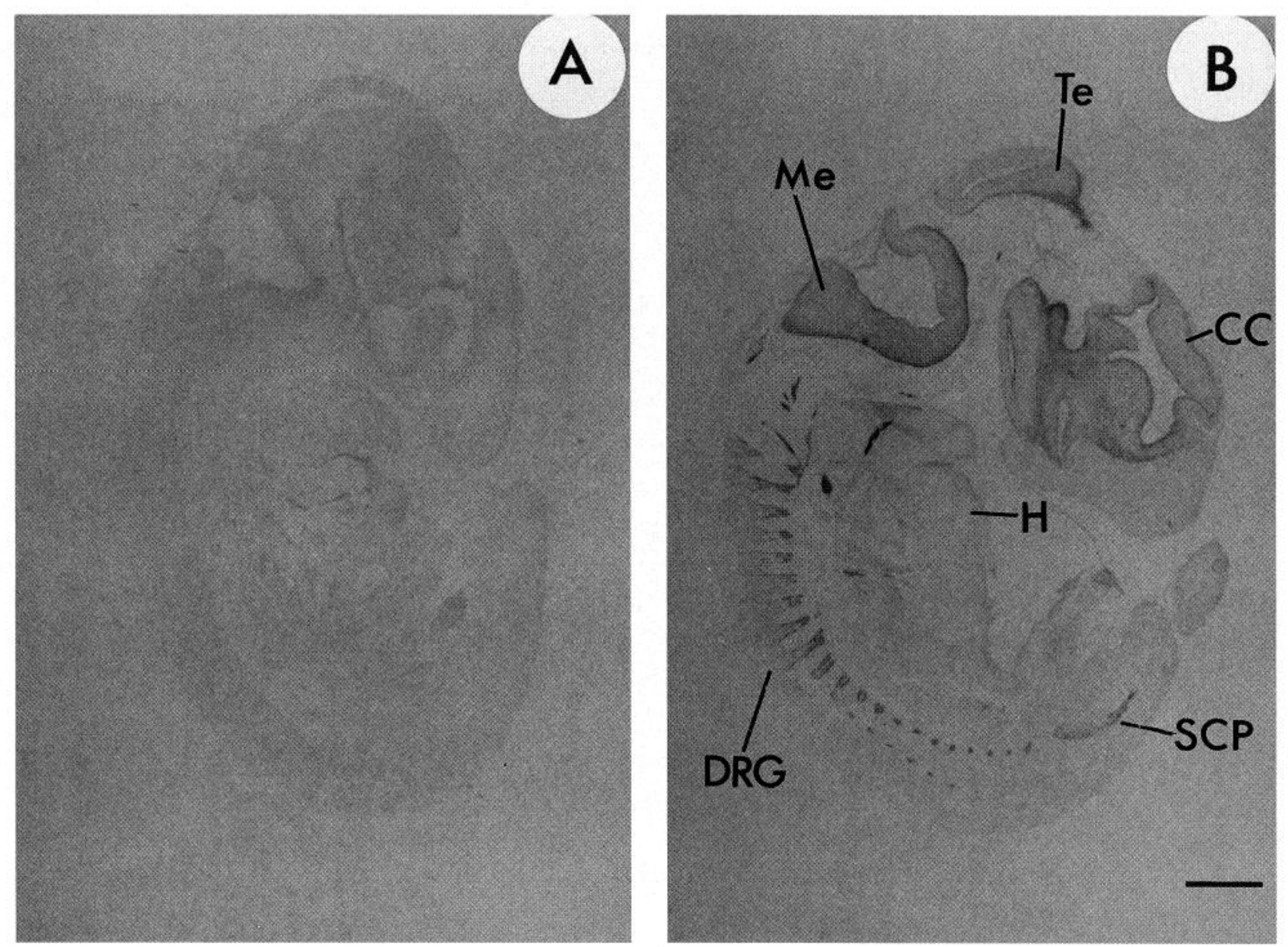

Figure 3. Neural specificity of Tm-5 in the ED13 rat embryo. Parasagittal sections of the ED13 rat embryo were incubated with WS5/9d and visualized by the AP detection method. $A$, Preimmune serum (1:400); $B$, WS5/9d (1:400). Note the absence of staining of the visceral tissue and other non-nervous regions of the embryo. $D R G$, dorsal root ganglion; $M e$, medulla; $T e$, tectum; $C C$, cerebral cortex; $S C P$, sacrococcygeal plexus; $H$, heart. Scale bar, 1 mm.

sequences (Beisel and Kennedy, 1994) and are very similar in size. For the sake of simplicity, Tms identified by WS $\alpha / 9 \mathrm{c}$ will be referred to as TmBr-1/-3 and those identified by WS5/9d as Tm-5.

Western immunoblot analysis was used to characterize the specificity of two new antisera, WS $5 / 9 \mathrm{~d}$ and WS $\alpha / 9 \mathrm{c}$. The initial criteria used to determine whether the antisera were identifying the correct isoforms were tissue specificity and apparent molecular weight $\left(M_{\mathrm{r}}\right)$ on SDS-PAGE. The peptide immunogen, modeled on a segment of the exon $9 \mathrm{~d}$ amino acid sequence derived from the $\alpha-\mathrm{Tm}_{\mathrm{s}}$ gene, is not conserved in Tms derived from other genes. Figure $2, A$ and $C$, shows that a single protein band migrating at $29-30 \mathrm{kDa}$ is identified by WS5/9d in chick and rat brain but is absent from rat skeletal muscle (Fig. $2 A$, lane 9). Previous data from our laboratories (and others) showed that Tm-5 migrates at $\sim 29 \mathrm{kDa}$ on SDS-PAGE and is absent from mature skeletal muscle (Lin et al., 1988; Schevzov et al., 1993). Testing the skeletal muscle sample for Tm immunoreactivity with the TM 311 antibody revealed that other Tm isoforms were present (not shown). Therefore the absence of the 29-kDa band from skeletal muscle is not because of the artifactual loss of Tm isoform immunoreactivity.

$\mathrm{WS} \alpha / 9 \mathrm{c}$ identifies two protein bands in the rat and mouse whole brain with apparent molecular weights of 30 and $34 \mathrm{kDa}$ (Fig. 2, $B$ and $D$ ). These bands are $\mathrm{TmBr}-3$ and $\mathrm{TmBr}-1$ proteins, respec- tively (both possess exon 9c, Lees-Miller et al., 1990), and they are also absent from rat muscle (Fig. 2B, lane 9), as expected with neuronal-specific molecules (Weinberger et al., 1993; Stamm et al., 1993). By comparison with an earlier study that also characterized an antiserum raised against the exon 9c sequence (Stamm et al., 1993), WS $\alpha / 9 \mathrm{c}$ identified protein bands with the same apparent molecular weight and tissue specificity. In addition, the absence of TmBr-1 in cerebellum was identified in both studies, and the targeted exon 9c sequence is not contained in Tm regions coded by other exons from the $\alpha$-Tm $\mathrm{f}_{\mathrm{f}}$ or other genes (GenBank search). Therefore, we can conclude that $\mathrm{WS} \alpha / 9 \mathrm{c}$ specifically recognizes only $\mathrm{Tm}$ isoforms that possess the sequence encoded by exon $9 \mathrm{c}$.

In the chicken cerebellar samples, three bands were identified at 30,32 , and $47 \mathrm{kDa}$ by the WS $\alpha / 9 \mathrm{c}$ antiserum (Fig. 2D, lane 2). The only exon 9c containing mRNA species identified in the chicken is BRT-1, which is transcribed from the $\beta$-Tm gene (Forry-Schaudies and Hughes, 1991). On the basis of the predicted amino acid sequence, it is larger than $\mathrm{TmBr}-1$, and therefore we tentatively suggest that the $47-50 \mathrm{kDa}$ band is BRT-1 protein in both species. The 30 and $32 \mathrm{kDa}$ bands are most likely to represent the chicken $\alpha-\mathrm{Tm}_{\mathrm{f}}$ equivalents of $\mathrm{TmBr}-3$ and $\mathrm{TmBr}-1$, respectively. The recognition of protein in the chicken forebrain sample was considerably weaker than equivalent rat brain samples (Fig. 2D, lanes 1 and 2), whereas the signal ob- 

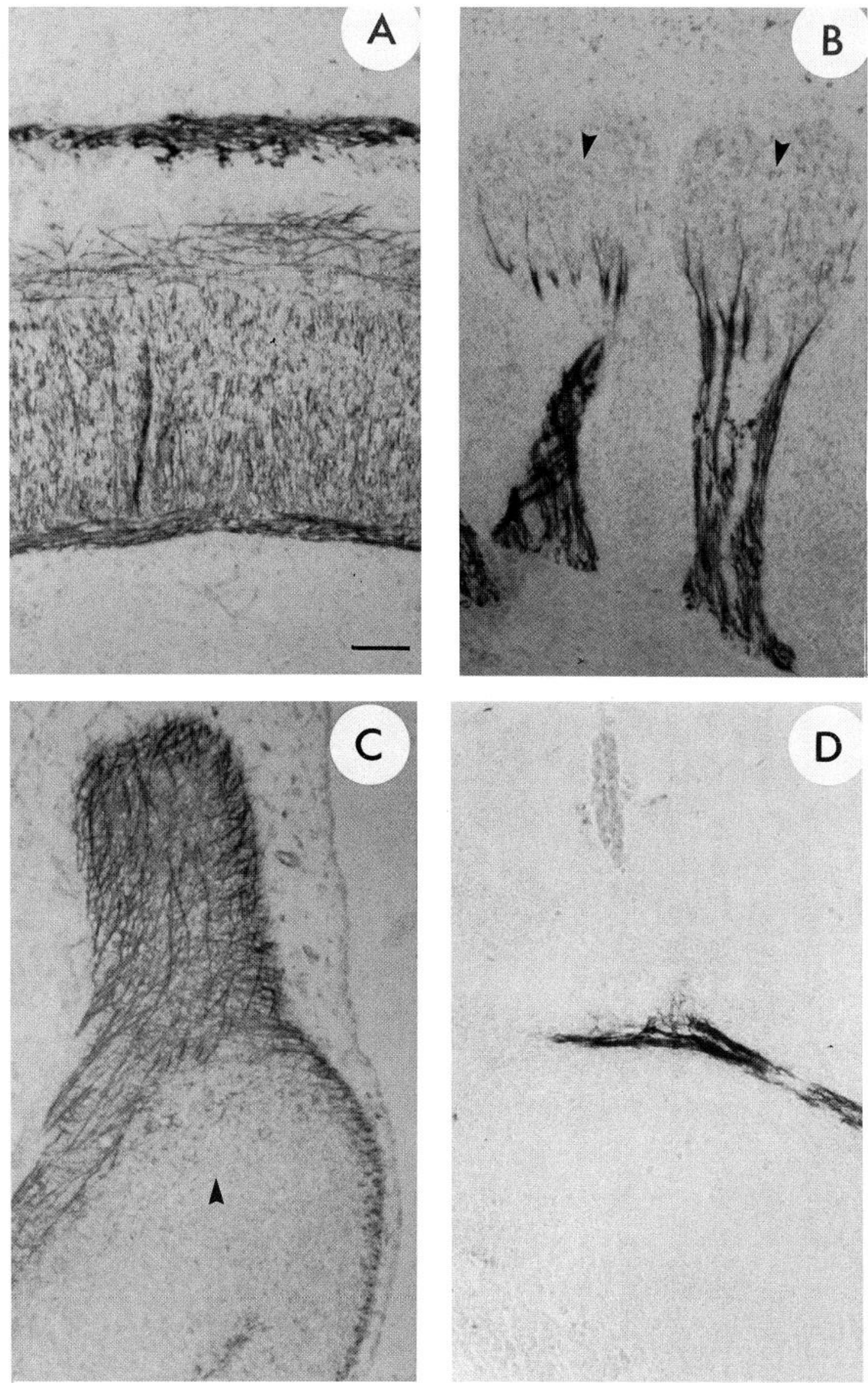

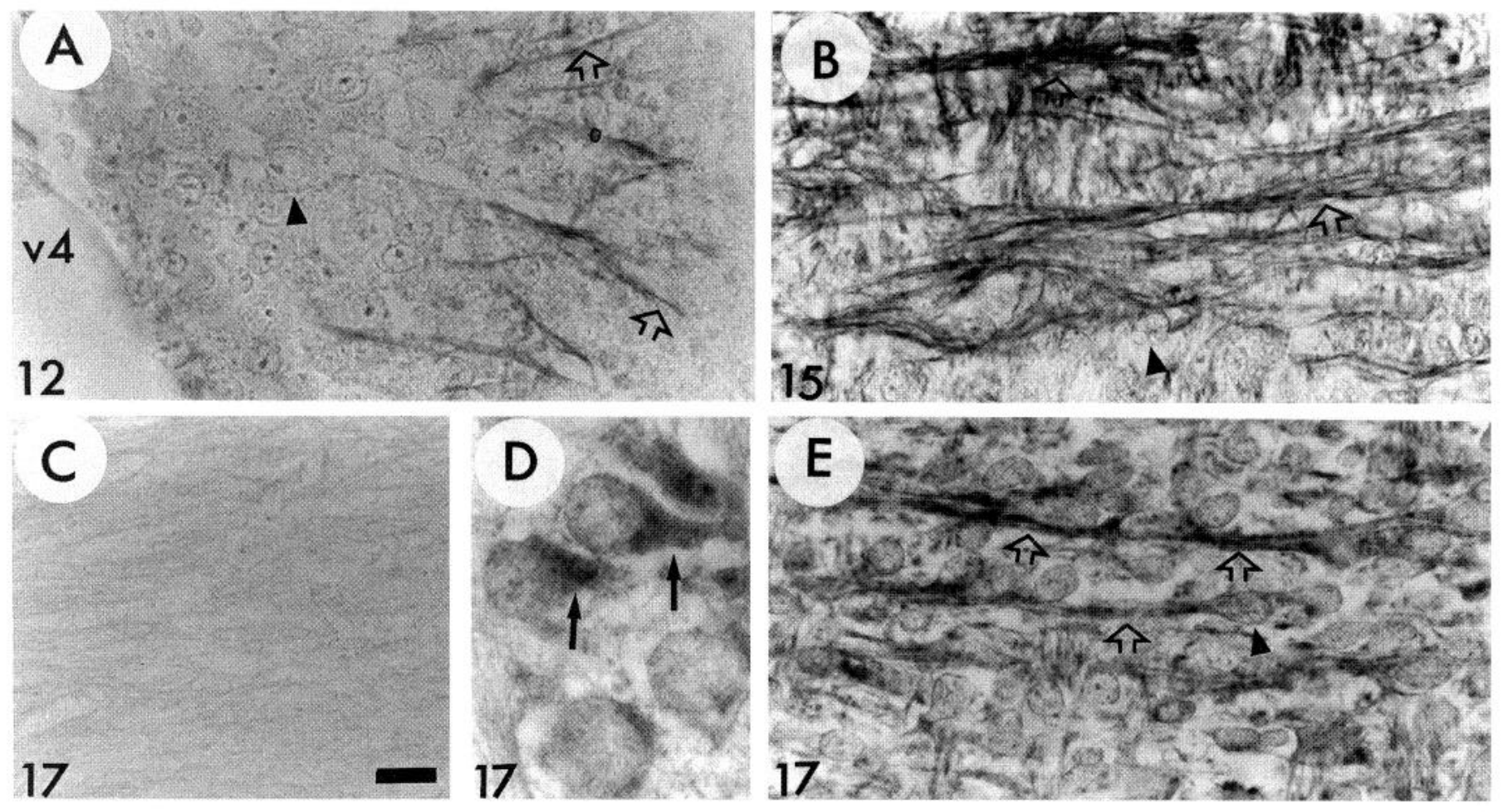

Figure 5. TmBr-1/-3 replaces Tm-5 in the maturing axons of the medulla. Parasagittal $(B-E)$ or transverse sections $(A)$ of embryonic rat brain were incubated with primary antisera WS5/9d for $A-D$ and with WS $\alpha / 9 \mathrm{c}$ for $E$, and immunoreactivity was visualized by the AP detection method, as described in Materials and Methods. Numbers on the left side of each panel represent embryonic ages. At ED12 $(A)$, axonal staining is clearly visible in the medulla (open arrow) in the earliest differentiating neurons, whereas immunoreactivity cannot be detected in the cell bodies (solid arrowhead). Tm-5 is absent from cells at the ventricular zone $(v 4)$ and postmitotic neuroblasts. At ED15 $(B)$, staining has increased because of the increase in axonal number and density (open arrow), although cell bodies are still not positive for Tm-5 (solid arrowhead). By ED17 $(C)$, axonal staining for Tm-5 is absent, whereas neuronal somata $(D$, arrows) are positive for the first time. However, at ED17 TmBr-1/-3 $(E)$, staining is now present on axons of the medulla, replacing Tm-5. Earlier developmental time points show no TmBr-1/-3 immunoreactivity in the medulla. Scale bar, $10 \mu \mathrm{m}$ for $A, B, C$, and $E$ and $16 \mu \mathrm{m}$ for $D$.

tained by immunohistochemistry was comparable between species (compare Figs. $6 B$ and $8 F$ ). It is possible that sequence differences between species become exaggerated in the denatured state of the Tms, resulting in lower avidity of Ig binding.

\section{Levels of $\mathrm{TmBr}-1 /-3$ and $\mathrm{Tm}-5 / 9 \mathrm{~d}$ are differentially regulated during rat nervous system development}

Figure $2 E$ represents the quantitation of Tm-5 and TmBr-3 levels in rat brain during development obtained by densitometrically scanning Western blots, one of which is shown in Figure 2, $A$ and $B$. Tm-5 was present at significant levels at embryonic day (ED) 11, the earliest time point assessed. Between ED11 and ED13, Tm-5 levels almost doubled and thereafter declined almost twofold to adult levels. In contrast to the early embryonic presence of $\mathrm{Tm}-5, \mathrm{TmBr}-1 /-3$ levels are barely detectable before ED17. In the period between ED17 and birth, TmBr-1/-3 levels more than doubled, with a subsequent additional increase after birth to the adult. Therefore, the developmental regulation of levels of these $\mathrm{Tm}$ isoforms is distinct during neuronal differentiation.

\section{Tm-5 is neuron-specific and exclusively localized to immature, growing axons in the early rat embryo}

Immunohistological analysis reveals that Tm-5 is widely distributed throughout the nervous system of the ED13 rat embryo and is virtually absent from non-neural tissue (Fig. $3 B$ ). Figure 4 shows the subcellular localization of Tm-5 in four different regions of the rat ED13 nervous system. Figure $4 A$ shows a dense network of axons in the spinal cord immunoreactive for Tm-5. (Fig. 4A). Similarly, intense axonal staining is seen with WS5/9d antiserum in the dorsal root ganglia (Fig. $4 B$ ) and tectum (Fig. $4 C$ ), whereas neuronal cell bodies are unstained (Fig. 4B,C, arrowheads). Tm-5 immunoreactivity is shown in a nerve bundle innervating the developing lower jaw of the embryo where axonal branching is visible (Fig. 4D). This localization pattern suggests an important role of Tm-5 in axonal development. In addition, the failure to detect Tm-5 in the cell bodies indicates spatial heterogeneity in microfilament composition at the early stages of neuronal differentiation that is associated with the development of neuronal polarity.

\section{Tm isoform replacement occurs rapidly between ED15 and ED17 in the rat embryonic medulla}

The absence of Tm-5 from undifferentiated neuroblasts is clearly visible in the ED12 medulla (Fig. $5 A$ ). At this stage of medullary development, early differentiating neurons can be identified at the marginal zone, and short axonal processes are clearly visible (open arrowheads, Fig. 5A). There is a developmental increase in the

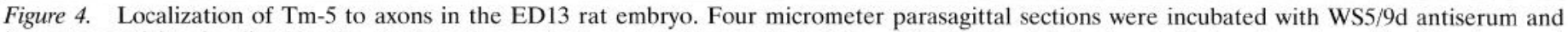

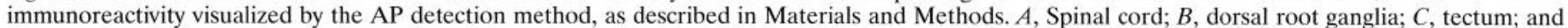

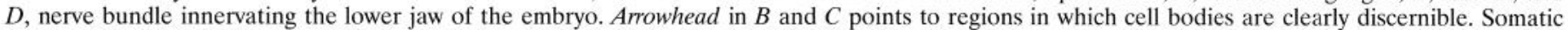

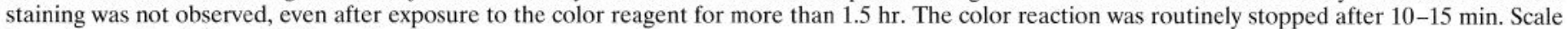
bars, $50 \mu \mathrm{m}$ for $A-C$ and $12.5 \mu \mathrm{m}$ for $D$. 

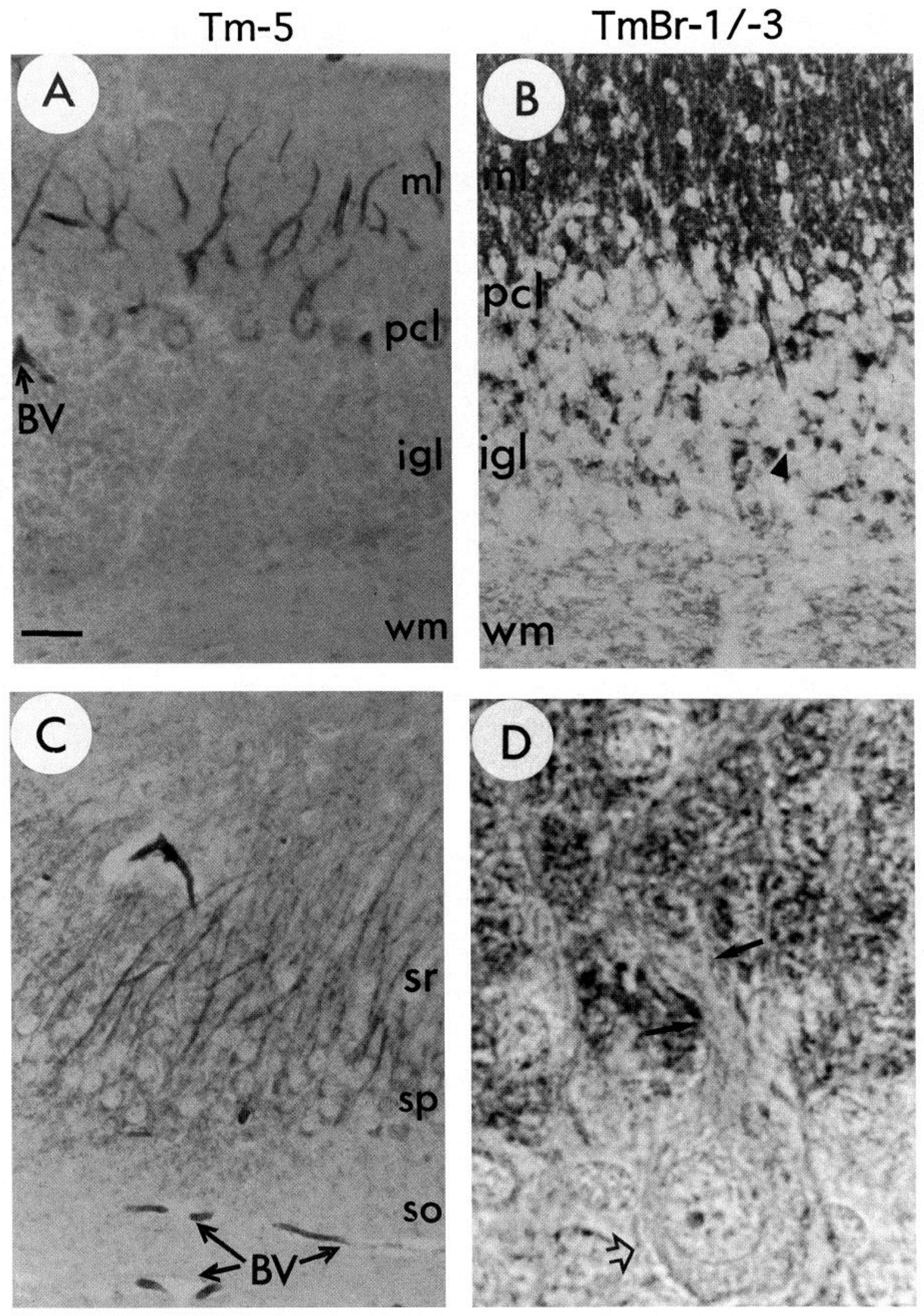

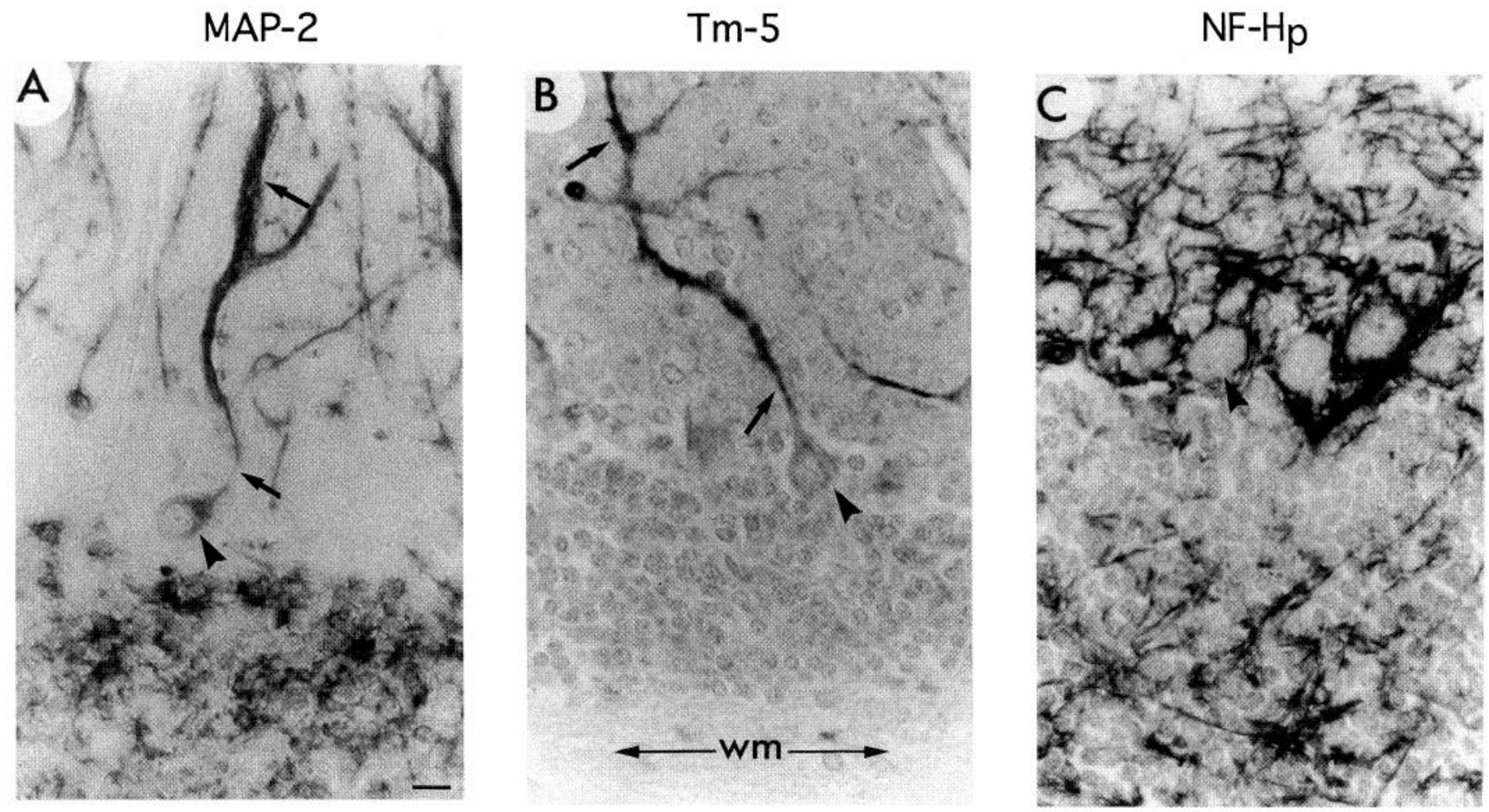

Figure 7. Comparison of Tm-5 distribution to MAP-2 and the phosphorylated isoform of NF-H $(N F-H p)$ in Purkinje neurons. The AP detection system was used to identify MAP-2 $(A), \mathrm{Tm}-5(B)$, and NF-Hp $(C)$ immunoreactivity in parasagittal sections of the cerebellum. Arrowheads point to Purkinje cell bodies and arrows follow the course of the central apical dendrite of the Purkinje cell. The staining distribution is almost identical for MAP-2 and Tm-5 in Purkinje cells. Note the absence of white matter staining $(\mathrm{wm})$ for Tm-5. NF-Hp, an axonal marker, shows a completely different distribution in the cerebellum, with axons coursing past the Purkinje cell bodies; axons are present in the molecular layer where the Purkinje cell dendrites reside. Scale bar in the bottom corner of $A, 20 \mu \mathrm{m}$.

staining of this brain region concomitant with an increase in axonal density until ED15 (Fig. 5B). By ED17, however, staining of axons in the medulla has almost completely disappeared (Fig. $5 C$ ), and for the first time we were able to visualize neuronal cell body positivity for Tm-5 (Fig. $5 D$, arrows). Therefore, within a $2 \mathrm{~d}$ period, Tm-5 is lost from axons in the medulla and appears on neuronal somata. However, the loss of Tm-5 immunoreactivity in axons is complemented by the appearance of $\mathrm{TmBr}-1 /-3$ immunoreactivity for the first time on these structures at ED17 (Fig. 5E, arrows). There is no staining for $\mathrm{TmBr}-1 /-3$ in the medulla at ED15 (not shown). This indicates that the composition of neuronal microfilaments in this short time period has been reorganized and that Tm isoform "switching" (or replacement) is occurring within different neuronal structures and most dramatically in the axons.

\section{$\mathrm{Tm}-5$ and $\mathrm{TmBr}-1 /-3$ show a distinct intracellular distribution in the adult CNS}

In contrast to the predominantly axonal staining seen in the early embryonic time points, the WS5/9d antibody detects Tm-5 only in the somatodendritic compartment of neurons in the adult rat brain. Figure $6 A$ shows the intracellular localization of Tm-5 in Purkinje cells of the cerebellum. Tm-5 was not observed in the white matter ( $\mathrm{wm})$, comprising axons of Purkinje neurons, incoming mossy fibers, and climbing fibers of the inferior olive. We were also unable to detect positive immunoreactivity of Purkinje cell axons emanating directly from the cell bodies even in $2 \mu \mathrm{m}$ sections (not shown) or in the parallel fibers (granule cell axons) that populate the molecular layer $(\mathrm{ml}$, Fig. $6 A)$. In contrast, the Purkinje cell bodies $(p c l)$ and their dendrites in the molecular

Figure 6. Tm-5 and TmBr-1/-3 are localized to specific structures within the adult rat brain. Parasagittal sections of adult rat brain were incubated with primary antisera (WS5/9d, $A$ and $C$; WS $\alpha / 9 \mathrm{c}, B$ and $D$ ) and immunoreactivity visualized by the AP detection method. $A, B$, and $D$ are cerebellum, and $C$ is hippocampus. Tm- 5 is somatodendritically localized in mature neurons, as seen in the Purkinje neurons of the cerebellum $(A)$ and pyramidal neurons of the CA3 region of the hippocampus ( $C$; regional confirmation was provided by the rat brain atlas of Paxinos and Watson, 1986). This somatodendritic localization was observed on all planes of section through the cerebellar folia. Axonal staining is absent in all regions of the cerebellum $(A)$ but is particularly noticeable in white matter $(\mathrm{wm})$ and the molecular layer $(\mathrm{ml})$. The hippocampal CA3 stratum radiatum $(C, s r)$ and the stratum oriens $(C$, so) are both devoid of axonal staining. The CA3 region receives a very dense axonal input from the mossy fibers of the dentate gyrus, which run perpendicular to the pyramidal cell dendrites. Staining of these axons is clearly absent in the $s r$. Punctate staining in the so therefore most likely represents the basal dendrites of the pyramidal neurons. In contrast, TmBr-1/-3 displays a very broad distribution within the cerebellum, although it is present at lower levels in the somatic cytoplasm and dendrites of Purkinje cells. Within the cerebellum $(B)$, parallel fibers that comprise much of the molecular layer $(m l)$ seem to be strongly positive, whereas the white matter axons $(\mathrm{wm})$ stain positively as well. $D$ shows a high-power micrograph of a Purkinje cell. The open arrow points to the cell soma, which is weakly positive for $\mathrm{TmBr}-1 /-3$ as is the apical dendrite (solid arrows). Much of the staining around the dendrites seems to be parallel fibers in cross section. $\mathrm{ml}$, molecular layer; $p c l$, Purkinje cell layer; igl, internal granular layer; $w m$, white matter; $B V$, blood vessel; arrowhead, glomerulus; sp, stratum pyramidale; so, stratum oriens. Scale bars, $40 \mu \mathrm{m}$ for $A-C$ and $10 \mu \mathrm{m}$ for $D$. 

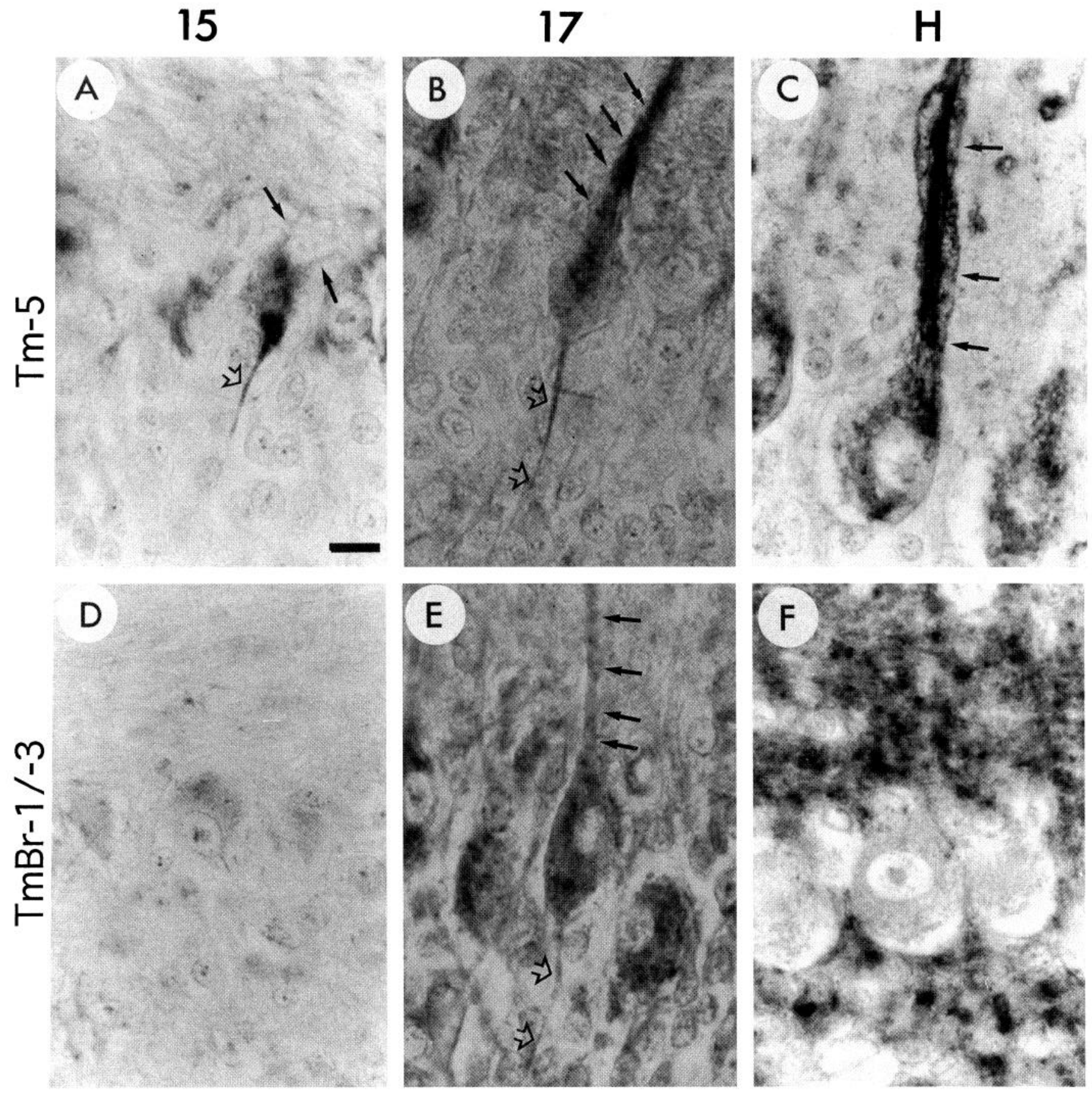

Figure 8. Localization of Tm-5 and TmBr-1/-3 in the developing chick cerebellum. Four micrometer parasagittal sections of chick cerebellum were incubated with WS5/9d $(A-C)$ and WS $\alpha / 9 \mathrm{c}(D-F)$ antisera. Immunoreactivity was visualized by the AP detection system. Solid arrows indicate dendrites, and open arrows point to axons. At ED15, Tm-5 $(A)$ is present predominantly on the axon of an immature Purkinje cell with a diminished staining of dendrites. By ED17 $(B)$, intense staining is present on both the axon and the dendrites of Purkinje cells. By hatch, the predominantly somatodendritic localization of Tm-5 is evident. This mature intracellular distribution of Tm-5 is similar to that observed in the rat (compare Fig. $6 A$ ). In contrast, $\mathrm{TmBr}-1 /-3$ is not present in ED15 Purkinje cells $(D)$. However, by ED17 $(E), \mathrm{TmBr}-1 /-3$ is present on both axons and dendrites of Purkinje cells. Therefore at ED17, TmBr-1/-3 and Tm-5 are localized to the same neuronal structures. By hatch, there is little staining of TmBr-1/-3 in the cell body in a manner that is similar to that observed in the adult neuron of the rat (compare Fig. 6, $B$ and $D$ ). From ED17 to hatch is a period during which the Tm isoforms segregate to their final, mature locations. Scale bar, $10 \mu \mathrm{m}$.

layer stained strongly with WS5/9d (Fig. 6A). This predominant somatodendritic localization of $\mathrm{Tm}-5$ seems to be consistent throughout the brain, as seen in hippocampal pyramidal neurons (Fig. 6C). The localization of Tm-5 was compared with MAP2, a somatodendritic marker (Matus et al., 1981; Caceres et al., 1984), and the phosphorylated form of the $200 \mathrm{kDa}$ neurofilament pro- tein (NF-Hp), an axonal marker (Sternberger and Sternberger, 1983). Within Purkinje cells, Tm-5 (Fig. 7B) showed an identical distribution to that of MAP2 (Fig. $7 A$ ), which contrasted to the axonal pattern observed with NF-Hp (Fig. 7C). Although we cannot rule out the presence of $\mathrm{Tm}-5$ from axons entirely, we conclude that $\mathrm{Tm}-5$ is overwhelmingly somatodendritic in local- 


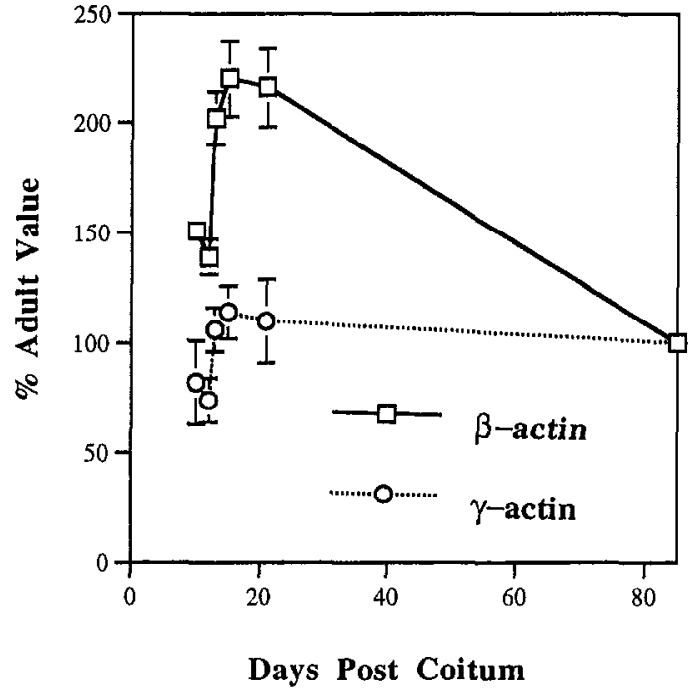

Figure 9. Levels of $\beta$ - and $\gamma$-actin during development of the rat brain. Samples of brain protein were subjected to SDS-PAGE and Western blot analysis. Values were expressed as arbitrary optical density units/microgram protein and then expressed as a percentage of the adult value for either $\beta$ - or $\gamma$ - actin (mean $\pm \mathrm{SD}, n=5$ ).

ization in the mature neuron. It should be noted that not all neurons stain strongly, because this antibody does not detect granule neurons in the cerebellum under these conditions, indicating that different classes of neurons possess varying levels of $\mathrm{Tm}-5$.

By contrast, $\mathrm{TmBr}-1 /-3$ seems to be predominantly present on axons in the cerebellum. Purkinje cell bodies and dendrites stain considerably weaker for $\mathrm{TmBr}-1 /-3$ (Fig. $6 D$, arrows) than do axons of the white matter (Fig. $6 B$ ) and parallel fiber axons surrounding the Purkinje cell dendrites (Fig. $6 D$ ). Cell bodies of granule neurons (igl, Fig. $6 B$ ) and within the molecular layer $(\mathrm{ml}$, Fig. $6 B$ ) also show little if any staining for $\mathrm{TmBr}-1 /-3$. The cerebcllar molccular layer revcals the grcatcst immunoreactivity for TmBr-1/-3 (Fig. 6B). The molecular layer is a region of intense synaptic activity and contains Purkinje, stellate, basket, and Golgi neuron dendrites, and stellate, basket, granule, and climbing fiber axons. Intense TmBr-1/-3 immunoreactivity is also present in the synaptic glomeruli of the internal granule layer $(\mathrm{igl})$, which are present between the granule cell bodies (Fig. 6B, arrowhead). This pattern of staining is similar to that obtained by Had et al. (1994) using a similar antibody raised to a synthetic peptide modeled on the $9 \mathrm{c}$ exon.

In summary, both $\mathrm{Tm}-5$ and $\mathrm{TmBr}-1 /-3$ show very different distributions in the adult rat brain. Tm-5 seems to be somatodendritic in localization in the brain in contrast to its axonal distribution in the embryo, whereas $\operatorname{TmBr}-1 /-3$ is present predominantly on axons, with considerably weaker staining seen on cell bodies and dendrites. These findings suggest that the localization of Tms contributcs to the development and maintenance of neuronal polarity.

\section{Tm isoform replacement in developing axons is conserved in evolution between birds and mammals}

The chick ccrcbcllum offers an excellent model of neuronal differentiation in which the histogenesis is largely conserved between birds and mammals. It also allows the developmental investigation of isoform localization within a clearly identifiable population of neurons, Purkinje cells. Our initial investigations showed that the distribution of Tm-5 and TmBr-1/-3 in the posthatch chick cerebellum was very similar to that of the mature rodent (compare Fig. $8 C, F$, with Fig. $6 A, D$ ). Therefore the cellular and intracellular specificities of these Tm isoforms is conserved between birds and mammals, providing strong evidence for the importance of these molecules in neuronal microfilament function and their potential role in the development of neuronal morphology.

At ED15, most chick Purkinje cells have stopped migrating from the interior of the cerebellum and are present in a relatively disorganized fashion around what latcr bccomes the Purkinjc ccll layer (Mugniani, 1969; Altman, 1972). Purkinje cells extend a clearly discernible axon during their migration, whereas at ED15 they do not yet possess the characteristic apical dendrite but instead display smaller, temporary dendrites (Fig. 8A) (Armengol and Sotelo, 1991). In ED15 Purkinje cells in which dendrites (Fig. $8 A$, solid arrows) and axons (Fig. $8 A$, clear arrows) were clearly discernible, Tm-5 was diminished in intensity in dendrites relative to the axon, confirming the predominantly axonal localization of this Tm during the early stages of neuronal differentiation seen in the rat. By ED17, intense staining of both the apical dendrite (Fig. $8 B$, solid arrows) and the axon (Fig. $8 B$, clear arrows) was observed. At hatch, Tm-5 showed a somatodendritic distribution (Fig. 8C) similar to that observed in the rat.

In contrast, $\mathrm{TmBr}-1 /-3$ was virtually absent from ED15 Purkinje cells (Fig. 8D) and was first observed in these neurons at ED17 (Fig. $8 E$ ). The delayed expression of this Tm isoform is similar to our earlier findings in the mammal. At ED17, $\mathrm{TmBr}-1 /-3$ is present throughout the Purkinje cell in both dendrites (Fig. $8 E$, solid arrows) and axons (Fig. $8 E$, clear arrows), which is similar to the pattern observed for Tm-5 (Fig. $8 B$ ). By hatch, the majority of TmBr-1/-3 staining is lost from the cell body, although there is strong staining of the molecular layer that is densely packed with axons. Staining of the axonal tracts in the white matter was clearly visible at hatch (not shown).

The colocalization of Tm-5 and TmBr-1/-3 reveals that ED17 is a critical period of microfilament reorganization within chick Purkinje cells, after which sorting and segregation of Tm-5 and TmBr-1/-3 into specific intracellular compartments occurs to produce an essentially adult pattern at hatch (Fig. $8 C, F$ ). The loss of Tm-5 from maturing axons and its replacement with $\mathrm{TmBr}-1 /-3$ seems to be a general phenomenon that is retained between the avian and mammalian central nervous systems.

\section{$\beta$-Actin levels are developmentally regulated in rat brain}

The developmental regulation of the Tm isoforms suggested that amounts of the actin isoforms change during development. Figure 9 shows the relative levels of $\beta$ - and $\gamma$-actin during rat brain development. The levels of $\gamma$-actin did not significantly alter from ED11 to adult. In contrast, a twofold downregulation of $\beta$-actin was observed between ED17 and adult. This downregulation was similar to that observed for Tm-5 (Fig. 2E).

\section{$\beta$-Actin is present in immature, developing axons but is absent from mature, quiescent axons}

To examine where the downregulation of $\beta$-actin was occurring, we investigated the immunohistochemical localization of $\beta$ - and $\gamma$-actin in the developing rat brain. Figure 10 shows the staining patterns of $\beta$ - and $\gamma$-actin at ED17 and adult in the medulla encompassing the period of decline in $\beta$-actin levels shown in Figure 9. Both $\beta$ - and $\gamma$-actin can be seen universally expressed on both axonal tracts (white 

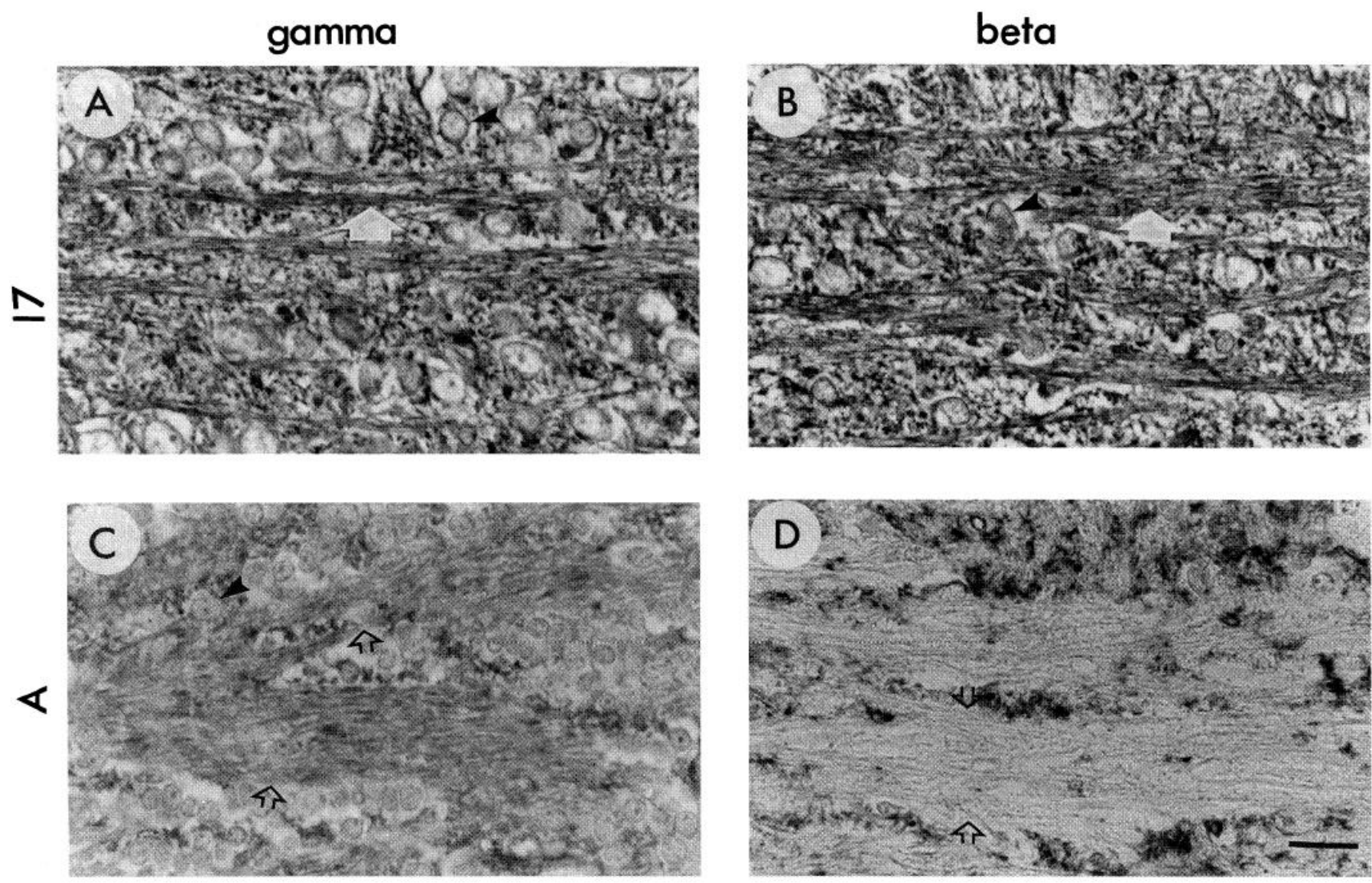

Figure 10. $\quad \beta$-Actin is lost from axons in the rat medulla between ED17 and adult. Parasagittal sections of rat brain were incubated with actin isoform specific antibodies (anti- $\beta$-actin, monoclonal mouse; $\gamma$-actin polyclonal rabbit), and immunoreactivity was visualized by the AP method. $\gamma$-Actin was present on all neuronal structures at $\operatorname{ED} 17(A)$, with axonal tracts clearly visible $(A$, white arrow). Similarly, $\beta$-actin showed a similar distribution at ED17 $(B)$. Both cell bodies $(B$, arrowhead $)$ and axonal tracts $(B$, white arrows $)$ showed $\beta$-actin immunoreactivity. By adult $(C)$, diffuse $\gamma$-actin staining could still be seen on cell bodies $(C$, arrow $)$ and axonal tracts $(C$, open arrows). However, $\beta$-actin was virtually absent from axons in the adult medulla $(D$, open arrows). Staining of these axonal tracts was slightly above that of background (compare to Fig. $4 C$ ). Scale bar, $15 \mu \mathrm{m}$.

arrows, Fig. 10, $B$ and $A$, respectively) as well as in cell bodies (Fig. $10 B$, arrowhead). By adult, $\gamma$-actin is still seen in axonal tracts of the medulla (Fig. 10C, clear arrows), and $\beta$-actin is virtually absent from axonal tracts (Fig. 10D, clear arrows).

Double-label immunofluorescence studies revealed that the relative absence of $\beta$-actin from axons was a widespread phenomenon in the adult brain. Figure 11 shows that although $\gamma$-actin was present at high levels in axonal tracts of the striatum and olfactory bulb (Fig. $11 A$ and asterisk in $C$ ), $\beta$-actin was absent from axons in these regions (Fig. $11 B, D$ ). However, $\beta$-actin was found in regions adjacent to the axonal tracts that contained cell bodies (Fig. $11 D$, open arrow), in glial cells (Fig. $11 B, D$, solid arrows), and in blood vessels (Fig. $11 B$, open arrow). The $\beta$-actin associated with mature Purkinje cell bodies is present in a discrete, punctate manner at the periphery of the cell body (Fig. $11 F$ ), which is in direct contrast to the broad distribution of $\gamma$-actin in these neurons (Fig. 11E). These studies indicate that the developmental downregulation of $\beta$-actin can be accounted for at least in part by the loss of $\beta$-actin from axons with increasing maturity, and that $\beta$-actin is associated with mature neurons in a highly specific distribution.

We conclude that both sets of Tm isoforms and $\beta$-actin are subject to specific patterns of segregation associated with axonal development and neuronal differentiation. This provides a potential molecular basis for the temporal and spatial specificity of microfilament function during neuronal differentiation.

Figure 11. Double-label immunolocalization of $\gamma$-and $\beta$-actin in the adult rat brain. Optical sections $(1 \mu \mathrm{m})$ with the confocal microscope were obtained from manually sectioned tissue that had been incubated with primary and fluorescent secondary antibodies essentially as described by Hill et al. (1994). $\gamma$-Actin data are presented in $A, C$, and $E$, and $\beta$-actin data are presented in $B, D$, and $F$. In striatal axon tracts, $\gamma$-actin intensely stains the axons $(A)$, whereas $\beta$-actin is absent in the axons but is present at high levels in glial cell bodies and processes (B, arrows) and in blood vessels (open arrows). For reference, an arrow in $A$ points to the same glial cell body indicated in $B$. In the olfactory bulb $(C), \gamma$-actin is broadly distributed and clearly visible in an axonal tract (asterisk) that appears as an "avenue" between regions containing cell bodies (open arrows). In contrast, $\beta$-actin ( $D$ ) is barely present on the axons, although staining for this isoform is strong in a glial cell within the tract and in the adjacent cell body-containing regions ( $D$, open arrow). In an oblique section through the cerebellum, two Purkinje cell layers can be visualized $(E, F)$. $\gamma$-Actin $(E)$ is present throughout the Purkinje cells and weaker in the cytoplasm and seems to be most intensely associated with the cell wall and the regions between the neurons. In contrast, $\beta$-actin $(F)$ staining appears in a punctate pattern associated with the cell membrane and is absent from the Purkinje cell cytoplasm. Scale bars, $10 \mu \mathrm{m}$. 


\section{gamma}
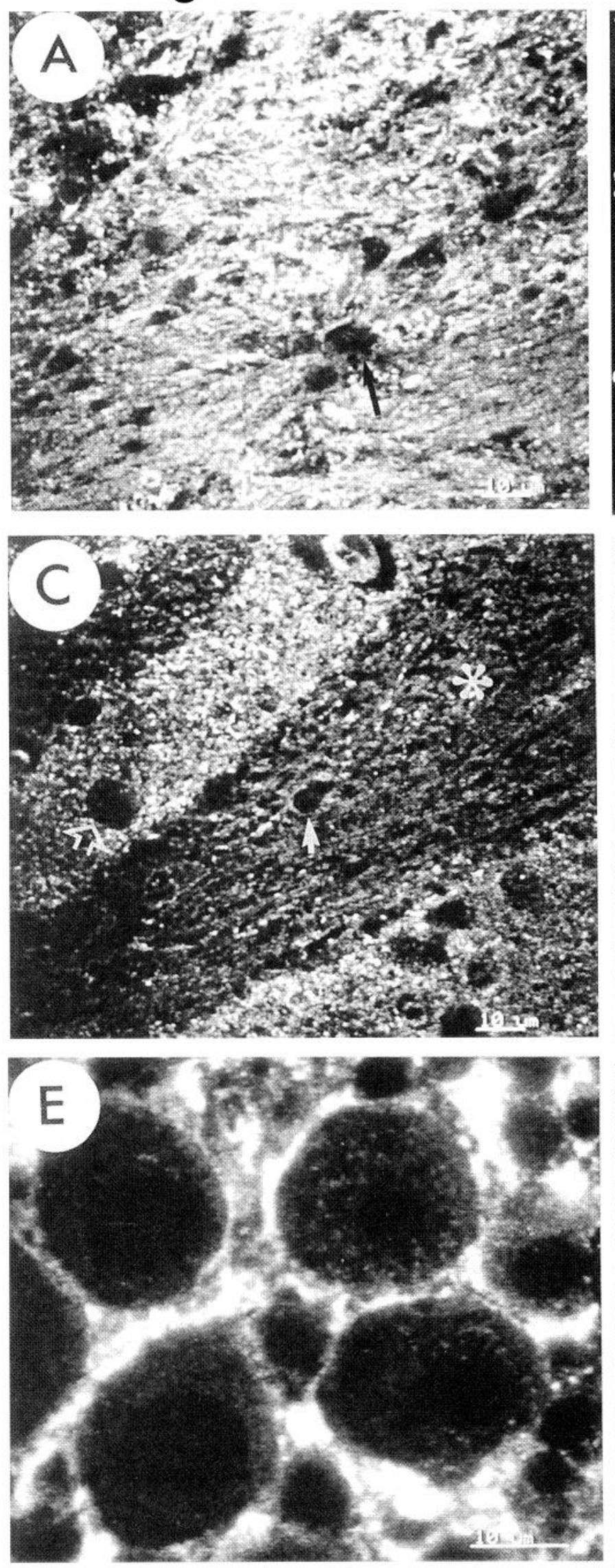

\section{beta}
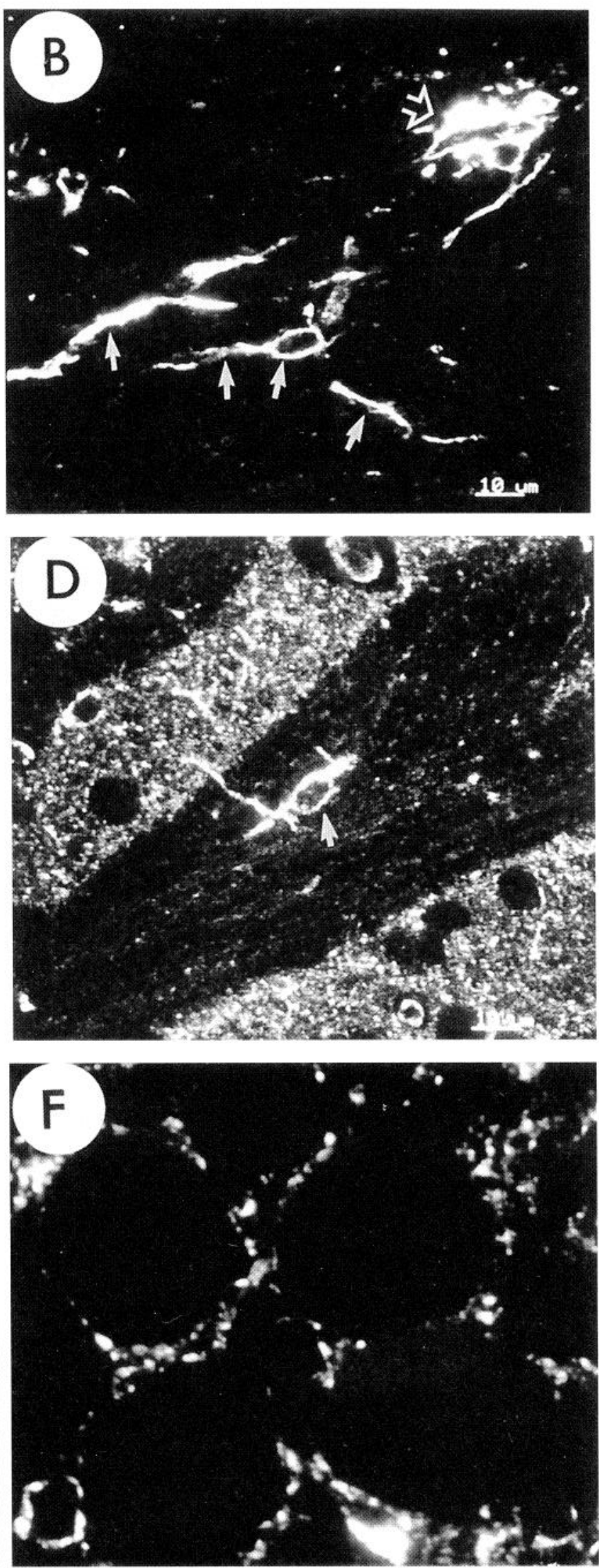
Figure 12. Summary of the developmental localization of $\mathrm{Tm}-5$, TmBr- $1 /-3$, and $\gamma$ - and $\beta$-actin. Intensity of staining is scored by the number of + symbols, with +++ indicating the strongest staining and - representing the absence of staining. $a$, axon; $a h$, axon hillock; $s$, soma; $d$, dendrites; $d$ ?, presence on dendrites is not clearly observed but inferred from the pattern of staining; N.S., not shown.

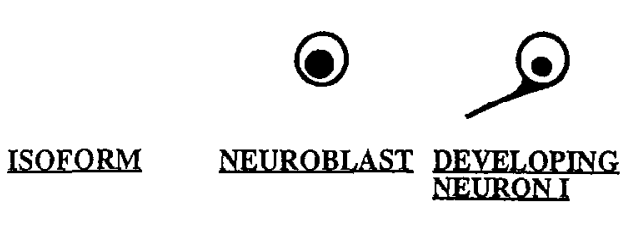

$\operatorname{Tm} \cdot 5$

$\operatorname{TmBr}-1 /-3$

$\beta$-actin

$\gamma$-actin

$-$

-
$++(s)$
$++(s)$

$+++(a)$

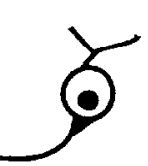

DEVELOPIN NEURONII

$+(s, d) ;++($ ah $)$ $++(a)$

$++(a, a h, s, d)$

N.S.

$++(\mathrm{a}, \mathrm{ah}, \mathrm{s})$

$+++(a, a h, s)$

N.S.
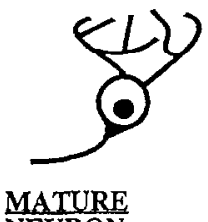

NEURON $+++(s, d)$

$+(s, d) ;+++(a)$

$+++(s, d ?)$

$+++(a, a h, s, d)$

\section{DISCUSSION}

\section{The molecular composition of neuronal microfilaments is spatially and temporally regulated}

Figure 12 summarizes the findings on localization of the actin and Tm isoforms from the neuroblast stage to the mature neuron. Both sets of Tm isoforms are absent from neuroblasts and are expressed only in response to neuronal differentiation. This is similar to the situation observed with $\mathrm{PC} 12$ cells stimulated to differentiate in the presence of nerve growth factor, where $\mathrm{TmBr}$ $1 /-3$ mRNA levels could be induced only under conditions in which the cells were able to differentiate into a neuronal phenotype (Weinberger et al., 1993). Which Tms are expressed in neuroblasts is not known. What is clear from this and our earlier studies (Weinberger et al., 1993) is that neuronal differentiation is accompanied by the expression of a unique repertoire of $\mathrm{Tm}$ isoforms.

In differentiating neurons of the rat embryo (developing neuron $I$, Fig. 12), there was a very tight spatial regulation of Tm-5. Tm-5 was expressed only in developing axons, being completely absent from the neuronal cell soma during the early stages of neuronal differentiation. This indicates that a specialized microfilament domain is associated with axonal development and neuronal polarity. This targeting of Tm-5 generally occurs well before dendrites have elaborated and seems to be independent of neuronal type. By comparison, the microtubule-associated protein, tau, does not seem to segregate to the axon until well after dendrites have been extended (Kosik and Finch, 1987).

Purkinje neurons clearly show the gradual shift in localization of Tm-5 from the axon in developing neurons to the somatodendritic compartment in the mature neuron (mature neuron, Fig. 12). In immature Purkinje neurons that have elaborated dendrites and axons (developing neuron II, Fig. 12), Tm-5 immunoreactivity is present throughout the cell, although at earlier stages it seems to be concentrated at the axonal pole. In the adult avian and rat brain, the localization of Tm-5 is clearly somatodendritic. This shift of Tm-5 from one pole of the neuron to the other is unusual, and to our knowledge has not been observed for any other cytoskeletal component. There are two possible explanations for these observations: (1) either a single isoform shifts from one location to the other; or (2) inasmuch as our Tm-5 antibody potentially recognizes two distinct molecules (NM1 and NM2, Fig. $1 B$ ), one molecule is lost from the axon (for example, NMI), whereas the other (for example, NM2) appears in the somatodendritic compartment. The latter is the simpler alternative, although our data at present cannot discriminate between them. Nevertheless, both alternatives indicate that the composition of adult axonal microfilaments is distinct from those in the soma and dendrites.

The loss of Tm-5 from axons is compensated for by its replacement with $\mathrm{TmBr}-1 /-3$. In the mature neuron, $\mathrm{TmBr}-1 /-3$ is found predominantly in the axon (mature neuron, Fig. 12), which is consistent with its being located presynaptically (Had et al., 1994). Based on our findings in the Purkinje neuron, however, $\mathrm{TmBr}-1 /-3$ is initially colocalized with $\mathrm{Tm}-5$ at the time that $\mathrm{Tm}-5$ has relocated to all neuronal compartments. This pattern of colocalization preceding segregation of Tm isoforms is similar to that observed in vitro for MAP-2 and tau (Kosik and Finch, 1987). It remains to be determined whether the mechanisms of targeting Tms and MAPs share common features.

The loss of one Tm isoform from axons and its replacement by another suggests that different isoforms compete for inclusion into specific structures. In vitro studies using yeast (Drees et al., 1995) and mammalian Tms produced in bacteria (Pittenger and Helfman, 1992) have shown that Tms can compete for binding to F-actin, which is the result of their varying strengths of interaction with actin filaments. With the synthesis of TmBr-1/-3 and its delivery to the axon, Tm-5 may not be able to compete as effectively for inclusion into axonal microfilaments, which could result in the preferential turnover of Tm-5 and its loss from axons. It is noteworthy that the localization of these two isoforms is reciprocal at each end of the developmental spectrum of the neuron. $\mathrm{TmBr}-1 /-3$ is present at lower levels in the adult Purkinje cell body and dendrites, possibly permitting $\mathrm{Tm}-5$ to compete effectively into somatodendritic microfilaments in the mature neuron. The competitiveness of any Tm isoform is likely to be a combination of how these molecules are targeted to cellular structures and their specific affinities for the actin polymer.

The molecular heterogeneity of microfilaments is not only defined by the spatial and temporal regulation of the Tms. The levels and localization of one of its two core components, $\beta$-actin, also vary in the developing brain. $\beta$-Actin is present in immature axons but is virtually absent from mature axons (mature neuron, Fig. 12). In addition, $\beta$-actin is distributed in a nonuniform punctate manner around the Purkinje cell soma. $\gamma$-Actin, however, is present throughout all observed regions of the developing and mature brain. Segregation of $\beta$ - and $\gamma$-actin has also been found in the gut (Yao et al., 1995) and in endothelial and fibroblast cell monolayers that have been wounded in vitro (Hoock et al., 1991). In contrast, tubulin isoforms, which are the primary components of microtubules, show no segregation between neuronal compartments in vivo (Ginzburg et al., 1985; Burgoyne et al., 1988). 


\section{Molecular heterogeneity may contribute to neuronal microfilament function and morphogenesis}

Actin filaments are enriched within dendritic spines (Fifkova and Delay, 1982; Matus et al., 1982; Caceres et al., 1983; Cohen et al., 1985). Although as yet untested, it has been suggested that these actin filaments function in harnessing molecules such as neurotransmitter receptors at their appropriate position on the postsynaptic surface and may modulate synaptic function (Fifkova and Delay, 1982; Matus et al., 1982). Within the squid giant axon there are microfilaments of varying lengths, orientation, and stability (Morris and Lasek, 1984; Fath and Lasek, 1988). Similarly, growth cones have at least two populations of microfilaments that differ in both polarity and organization (Lewis and Bridgman, 1992). These findings show that microfilaments exhibit structural heterogeneity and regionalization within neurons. The present study raises the possibility that the biochemical and structural properties of these microfilaments are a function of the type of Tm or actin isoforms present within a given neuronal compartment. Support for this hypothesis has been provided by a number of lines of evidence including in vitro assays, cell transfection, and mutant yeast studies, each of which is discussed below.

A number of mammalian $\mathrm{Tm}$ isoforms can differentially regulate the stability of actin filaments by protecting against the actin-severing properties of gelsolin and binding actin with different affinities (Ishikawa et al., 1989; Pittenger and Helfman, 1992). Nonmuscle $\mathrm{Tm}$ isoforms can also differentially regulate other biochemical properties of microfilaments, including the magnesium-dependent ATPase activity associated with myosin (for review, see Pittenger et al., 1994).

Recent studies have implicated Tms in the regulation of cell shape and development. In yeast, deletion of a major $\mathrm{Tm}$ isoform resulted in the loss of actin cables and the disruption of vesicular transport and development (Liu and Bretscher, 1989, 1992). Warren et al. (1995) showed that transfection of a chimeric Tm-5/Tm-3 DNA into CHO cells resulted in aberrant cell division and cytokinesis. Based on earlier work (Novy et al., 1993), which showed that the chimeric protein possesses a very high affinity for actin filaments and can displace Tm-5 and Tm-3, the authors suggested that the chimeric $\mathrm{Tm}$ is functioning in a dominant negative fashion to disrupt microfilament function. These studies combined with our localization data suggest that Tms play specific roles in the control of microfilament organization within distinct neuronal compartments.

Transfection of the human $\beta$-actin gene into $C 2$ myoblasts resulted in increased cell size and spreading. In addition, $\beta$-actin protein is present and its mRNA is concentrated in the motile ruffling edges of fibroblasts under normal conditions (Hill et al., 1994; Kislauskis et al., 1994). When the targeting of $\beta$-actin mRNA to the cell periphery is disrupted and consequently levels of $\beta$-actin in this peripheral pool decrease, the organization of microfilaments at the leading edge, as well as cell morphology, is altered (Kislauskis et al., 1994). These findings provide strong evidence for a role of $\beta$-actin in membrane modeling that seems to be at least partially dependent on the availability of $\beta$-actin mRNA. The presence of $\beta$-actin in the developing but not the mature axon therefore may reflect a role in membrane growth that is no longer required in the adult neuron.

In summary, we have shown that the molecular composition of neuronal microfilaments is both spatially and temporally regulated. The molecular diversity of microfilaments may provide altered structural properties that could generate unique morpho- logical patterns in neurons. In particular, specialized microfilament domains may be associated with the development and maintenance of neuronal polarity.

\section{REFERENCES}

Altman J (1972) Postnatal development of the cerebellar cortex in the rat. II. Phases in the maturation of Purkinje cells and of the molecular layer. J Comp Neurol 145:399-464.

Armengol J-A, Sotelo C (1991) Early dendritic development of Purkinje cells in the rat cerebellum. A light and electron microscopic study using axonal tracing in "in vitro" slices. Dev Brain Res 64:95-114.

Beisel NW, Kennedy JE (1994) Identification of novel alternatively spliced isoforms of the tropomyosin-encoding gene, $\mathrm{TM}_{\mathrm{nm}}$, in the rat cochlea. Gene 145:251-256.

Burgoyne RD, Cambray-Deakin MA, Lewis SA, Sarkar S, Cowan N (1988) Differential distribution of $\beta$-tubulin isotypes in cerebellum. EMBO J 7:2311-2319.

Caceres A, Binder LI, Payne MR, Bender P, Steward O (1983) Immunocytochemical localization of actin and microtubule associated protein (MAP2) in dendritic spines. Proc Natl Acad Sci USA 80:1738-1742.

Caceres A, Binder LI, Payne MR, Bender P, Rebhun L, Steward O (1984) Differential subcellular localization of tubulin and the microtubule associated protein MAP2 in brain tissue as revealed by immunocytochemistry with monoclonal hybridoma antibodies. J Neurosci 4:394-410.

Clayton L, Reinach FC, Chumbley GM, Macleod AR (1988) Organization of the $\mathrm{hTm}_{\mathrm{nm}}$ gene. Implications for the evolution of muscle and non-muscle tropomyosins. J Mol Biol 201:507-515.

Cohen RS, Chung SW, Pfaff BW (1985) Immunocytochemical localization of actin in dendritic spines of the cerebral cortex using colloidal gold as a probe. Cell Mol Neurobiol 5:271-284.

DeNofrio D, Hoock TC, Herman IM (1989) Functional sorting of actin isoforms in microvascular pericytes. J Cell Biol 109:191-202.

Drees B, Brown C, Barrell BG, Bretscher A (1995) Tropomyosin is essential in yeast, yet the TPM1 and TPM2 products perform distinct functions. J Cell Biol 128:383-392.

Fath KR, Lasek RJ (1988) Two classes of actin microfilaments are associatcd with the inncr cytoskeleton of axons. J Cell Biol 107:613-621.

Fifkova E, Delay RJ (1982) Cytoplasmic actin in neuronal processes as a possible mediator of synaptic plasticity. J Cell Biol 95:345-350.

Forry-Schaudies S, Hughes SH (1991) The chicken tropomyosin 1 gene generates nine mRNAs by alternative splicing. J Biol Chem 266: 13821-13827.

Ginzburg I, Behar L, Littauer UZ, Griffin WST (1985) Differential localization of microtubules in cerebellar cells. J Neurosci 9:1961-1967.

Had L, Faivre-Sarrailh C, Legrand C, Mery J, Brougidou J, Rabie A (1994) Tropomyosin isoforms in rat neurons: the different developmental profiles and distributions of TM-4 and TMBr-3 are consistent with different functions. J Cell Sci 107:2961-2973.

Hill MA, Schedlich L, Gunning P (1994) Serum induced signal transduction determines the peripheral location of $\beta$-actin mRNA within the cell. J Cell Biol 127:1221-1230.

Hoock TC, Newcomb PM, Herman IM (1991) $\beta$ actin and its mRNA are localized at the plasma membrane and the regions are moving cytoplasm during the cellular response to injury. J Cell Biol 112:653-664.

Ishikawa R, Yamashiro S, Matsumura F (1989) Differential modulation of actin-severing activity of gelsolin by multiple isoforms of cultured rat cell tropomyosin. J Biol Chem 264:7490-7497.

Kislauskis EH, Zhu X, Singer RH (1994) Sequences responsible for intracellular localization of $\beta$-actin messenger RNA also affect cell phenotype. J Cell Biol 127:441-445.

Kosik KS, Finch EA (1987) MAP2 and tau segregate into dendritic and axonal domains after the elaboration of morphologically distinct neurites: an immunocytochemical study of cultured rat cerebrum. J Neurosci 7:3142-3153.

Lees-Miller JP, Goodwill LO, Helfman DM (1990) Three novel brain tropomyosin isoforms are expressed from the rat $\alpha$-tropomyosin gene through the use of alternative promoters and alternative RNA processing. Mol Cell Biol 10:1729-1742.

Lewis AK, Bridgman PC (1992) Nerve growth cone lamellapodia contain two populations of actin filaments that differ in organization and polarity. J Cell Biol 119:1219-1243. 
Lin JJ-C, Hegmann TE, Lin JL-C (1988) Differential localization of tropomyosin isoforms in cultured non-muscle cells. J Cell Biol 107: 563-572.

Liu H, Bretscher A (1989) Disruption of the single tropomyosin gene in yeast results in the disappearance of actin cables from the cytoskeleton. Cell 57:233-242.

Liu H, Bretscher A (1992) Characterization of TpMI disrupted yeast cells indicates an involvement of tropomyosin in directed vesicular transport. J Cell Biol 118:285-299.

Lloyd C, Schevzov G, Gunning P (1992) Transfection of non-muscle $\beta$ and $\gamma$-actin genes into myoblasts elicits different feedback regulatory responses from endogenous actin genes. J Cell Biol 117:787-797.

Matus A, Bernhardt R, Hugh-Jones T (1981) High molecular weight microtubule associated proteins are preferentially associated with dendritic microtubules in brain. Proc Natl Acad Sci USA 780:3010-3014.

Matus A, Ackcrmann M, Pchling G, Bycrs HR, Fujiwara K (1982) High actin concentrations in brain dendritic spines and post synaptic densities. Proc Natl Acad Sci USA 79:7590-7594.

Mooseker MS, Bonder EM, Grimwade BG, Howe CL, Keller T, Wasserman RH, Wharton KA (1981) Regulation and contractility, cytoskeletal structure and filament assembly in the brush border of intestinal epithelial cells. Cold Spring Harbor Symp 46:355-365.

Morris J, Lasek R (1984) Monomer-polymer equilibria in the axon: direct measurement of tubulin and actin as polymer monomer in axoplasm. J Cell Biol 98:2064-2076.

Mugniani E (1969) Ultrastructural studies on the cerebellar histogenesis. II. Maturation of nerve cell populations and establishment of synaptic connections in the cerebellar cortex of the chick. In: Neurobiology of cerebellar evolution and development (Lunas R, ed), pp 749-782. Chicago: American Medical Association.

North AJ, Gimona M, Lando Z, Small JV (1994) Actin isoform compartments in chicken gizzard smooth muscle cells. J Cell Sci 107:445-455.

Novy RE, Sellers JR, Liu L-F, Lin JJ-C (1993) In vitro functional characterization of bacterially expressed human fibroblast tropomyosin isoforms and their chimeric mutants. Cell Motil Cytoskel 26:248-261.
Paxinos G, Watson C (1986) The rat brain in stereotaxic coordinates. London: Academic.

Pittenger MF, Helfman C (1992) In vitro and in vivo characterization of four fibroblast tropomyosins produced in bacteria: TM-2, TM-3, TM-5a and TM-5b are colocalized in interphase fibroblasts. J Cell Biol 118:841-858.

Pittenger MF, Kazzaz JA, Helfman DM (1994) Functional properties of non-muscle tropomyosin isoforms. Curr Opin Cell Biol 6:96-104.

Schevzov G, Lloyd C, Gunning P (1992) High level expression of transfected $\beta$ - and $\gamma$-actin genes differentially impact on myoblast cytoarchitecture. J Cell Biol 117:775-786.

Schevzov G, Lloyd C, Hailstones D, Gunning P (1993) Differential regulation of tropomyosin isoform organization and gene expres-sion in response to altered actin gene expression. J Cell Biol 121:811-821.

Sheppard AM, Konopka M, Jeffrey PL (1988) The developmental appearance of Thy-1 in the avian cerebellum. Dev Brain Res 40:181-192.

Stamm S, Casper D, Lees-Miller J, Helfman DH (1993) Brain-specific tropomyosins TMRr-1 and TMRr-3 have distinct patterns of expression during development and in adult brain. Proc Natl Acad Sci USA 90:9857-9861.

Sternberger LA, Sternberger NII (1983) Monoclonal antibodies distinguish phosphorylated and nonphosphorylated forms of neurofilaments in situ. Proc Natl Acad Sci USA 80:6126-6130.

Taylor EW (1979) Mechanism of actomyosin ATPase and the problem of muscle contraction. Crit Rev Biochem 6:101-163.

Warren KS, Lin JL-C, McDermott JP, Lin JJ-C (1995) Forced expression of chimeric human fibroblast tropomyosin mutants affects cytokinesis. J Cell Biol 129:697-708.

Weinberger RP, Henke RC, Tolhurst O, Jeffrey PL, Gunning P (1993) Induction of neuron-specific tropomyosin mRNAs by nerve growth factor is dependent on morphological differentiation. J Cell Biol $120: 205-215$.

Yao X, Chaponnier C, Gabbiani G, Forte JG (1995) Polarized distribution of actin isoforms in gastric parietal cells. Mol Biol Cell 6:541-557. 